\title{
Nucleation and growth study of copper thin films on different substrates and wetting layers by metal-organic chemical vapour deposition ${ }^{\dagger}$
}

\author{
A DUTTA, J GOSWAMI and S A SHIVASHANKAR \\ Materials Research Centre, Indian Institute of Science, Bangalore 560012, India \\ Abstract. Chemical vapour deposition of copper thin films on different diffusion barrier/ \\ adhesion promoter layers have been studied. Copper thin films were grown in low pressure \\ $\mathrm{CVD}$ reactor, using $\mathrm{Cu}(\mathrm{dpm})_{2}$ as precursor and argon as carrier gas. Growth rates, film \\ adhesion to the substrate, and surface morphology were studied in detail.
}

Keywords. Chemical vapour deposition; copper thin film; surface morphology.

\section{Introduction}

Metal-organic chemical vapour deposition (MOCVD) has potential application in the metallization of microelectronic circuits. It gives good conformal coverage over small dimensions, even over high aspect ratio trenches, which is very difficult by any physical vapour deposition process. With rapid advances in high density integrated circuits, the interconnection metal has also become a subject of concern. $\mathrm{Cu}-\mathrm{Si}-\mathrm{Al}$ alloy, used widely for interconnection, becomes unusable because of its high resistivity $(3.4 \mu \Omega-\mathrm{cm})$ and low resistance to electromigration. Copper, with lower resistivity $(1 \cdot 7 \mu \Omega-\mathrm{cm})$ and higher resistance to electromigration is a promising metal for interconnection (Ohmi and Tsubouchi 1992; Murarka et al 1993). Hence, MOCVD of copper is being studied extensively (Kaloyeros and Fury 1993). However, copper has its drawbacks: it oxidizes rapidly and diffuses easily into silicon dioxide (Schum-Diamand et al 1993) and silicon substrates (Weber 1988). Copper acts as a deep level dopant in silicon (Sze 1985), and if present near the interface, it gives rise to a large junction leakage current. Moreover, MOCVD-grown copper films show low adhesion to substrates (Kaloyeros and Fury 1993) making it more difficult to use in device processing technology. To overcome all these problems, a barrier layer/wetting layer has been proposed (Ding et al 1994). This barrier layer/wetting layer should stop $\mathrm{Cu}$-diffusion to the substrate.

In view of the above requirements, we have studied the growth and surface morphology of MOCVD-grown copper films. Our effort was focused on a comparative study of nucleation, growth and surface morphology of MOCVD-grown copper films on $\mathrm{SiO}_{2} / \mathrm{Si}$ substrate without any barrier layer/wetting layer and with a metal barrier layer/wetting layer. The diffusion barrier/adhesion promoter layers chosen were: low-melting aluminium ( $\mathrm{Al}$ ), high-melting chromium $(\mathrm{Cr})$ and the refractory metal molybdenum (Mo).

We have found a slower growth rate on metal barrier layer/wetting layers compared to $\mathrm{SiO}_{2} / \mathrm{Si}$. The surface morphology of the films were found to be very different on different barrier layer/wetting layers. Based on our findings, chromium and aluminium seem to be effective wetting layers for MOCVD-growth of copper films on $\mathrm{SiO}_{2} / \mathrm{Si}$ substrates.

\footnotetext{
${ }^{\dagger}$ Paper presented at the poster session of MRSI AGM VI, Kharagpur, 1995
} 


\section{Experimental}

\subsection{Deposition of diffusion barrier/adhesion promoter layers}

Thermally oxidized silicon wafers of $2 \mathrm{~cm} \times 2 \mathrm{~cm}$ were used as substrate. The thickness of thermal oxide was around $1 \mu \mathrm{m}$. These wafers were cleaned in boiling trichloroethylene followed by acetone and methanol. After cleaning, the wafers were kept at $450^{\circ} \mathrm{C}$ in a furnace for $15 \mathrm{~min}$, before loading into the deposition system.

$\mathrm{Cr}$ films were deposited by resistive evaporation under cold substrate conditions. $\mathrm{Cr}$ was evaporated from a tungsten wire basket loaded with ultra high purity chromium metal nuggets. The pressure during evaporation was $10^{-2}$ Torr. Because chromium sublimes and sputters, heating was done in short pulses. These pulses were controlled manually by adjusting the current. This process was found to give better films than constant heating. The films were $1100 \AA-1200 \AA$ thick.

Deposition of aluminium was also performed in the same setup. A tungsten filament loaded with ultra high purity aluminium wire was used as source. Film thickness was $1200 \AA-1400 \AA$.

Molybdenum films were deposited using a rf sputtering system in which the substrate was kept on a holder placed under the target. Deposition was done under cold substrate conditions. The Mo films deposited were $1000 \AA-1100 \AA$ thick.

All these metal films were characterized by $\mathrm{X}$-ray diffraction and resistivity measurements. Scanning electron microscopy was performed to examine surface quality of the films. All metal films were found to be very smooth having an average grain size below $0.01 \mu \mathrm{m}$. Different parameters of these films are summarized in table 1 . These metal films were stored in a vacuum desiccator and used for the study of copper film growth.

\subsection{MOCVD of copper}

MOCVD of copper was carried out in a vertical reactor built in our laboratory. A schematic of the reactor used is given in figure 1. This reactor consists of five main parts: (1) source or bubbler for evaporation of precursor materials, (2) gas lines with mass flow controller (MFC) and valves to enable precise control of carrier gas flow, (3) reactor chamber with IR-heated substrate holder and a graphite susceptor with an embedded thermocouple, (4) temperature controllers to enable precise temperature

Table 1. Comparison of properties of metals used as diffusion barrier/adhesion promoter layer.

\begin{tabular}{|c|c|c|c|}
\hline \multirow[b]{2}{*}{ Properties } & \multicolumn{3}{|c|}{ Metal } \\
\hline & $\mathrm{Cr}$ & $\mathrm{Al}$ & Mo \\
\hline Resistivity & $13 \cdot 5 \mu \Omega-\mathrm{cm}$ & $4 \cdot 0 \mu \Omega-\mathrm{cm}$ & $100 \mu \Omega-\mathrm{cm}$ \\
\hline Crystallinity & polycrystalline & polycrystalline & polycrystalline \\
\hline Grain size & $<0.01 \mu \mathrm{m}$ & $<0.01 \mu \mathrm{m}$ & $<0.01 \mu \mathrm{m}$ \\
\hline Lattice & $\operatorname{bcc}(a=2.88 \AA)$ & $f \mathrm{cc}(\mathrm{a}=4.05 \AA)$ & $\mathrm{bcc}(\mathrm{a}=3.15 \AA)$ \\
\hline Melting point & $1860^{\circ} \mathrm{C}$ & $660^{\circ} \mathrm{C}$ & $2617^{\circ} \mathrm{C}$ \\
\hline Layer thickness & $1400 \AA$ & $1200 \AA$ & $1100 \AA$ \\
\hline
\end{tabular}


control of the substrate, bubbler and the gas lines and (5) vacuum pump with capacitance manometer and throttle valve to enable pressure control.

Copper deposition was carried out using bis-[dipivaloylmethanato] $\mathrm{Cu}(\mathrm{II})$ or $\mathrm{Cu}(\mathrm{dpm})_{2}$ as precursor. This precursor was synthesized in our laboratory and was found to be of high purity on elemental analysis (Goswami et al 1994). This metalorganic complex is a crystalline solid at room temperature, and sublimes at temperatures exceeding $80^{\circ} \mathrm{C}$. Several grams of the precursor were crushed into fine powder and placed in the stainless steel bubbler. Ultra high purity argon gas was used as carrier gas for the experiments. For study of nucleation and growth, deposition was carried out for different durations using optimum deposition conditions (table 2). Different thicknesses of films were deposited on $\mathrm{Cr} / \mathrm{SiO} 2 / \mathrm{Si}, \mathrm{Al} / \mathrm{SiO}_{2} / \mathrm{Si}, \mathrm{Mo} / \mathrm{SiO}_{2} / \mathrm{Si}$ as well as uncoated $\mathrm{SiO}_{2} / \mathrm{Si}$ wafers.

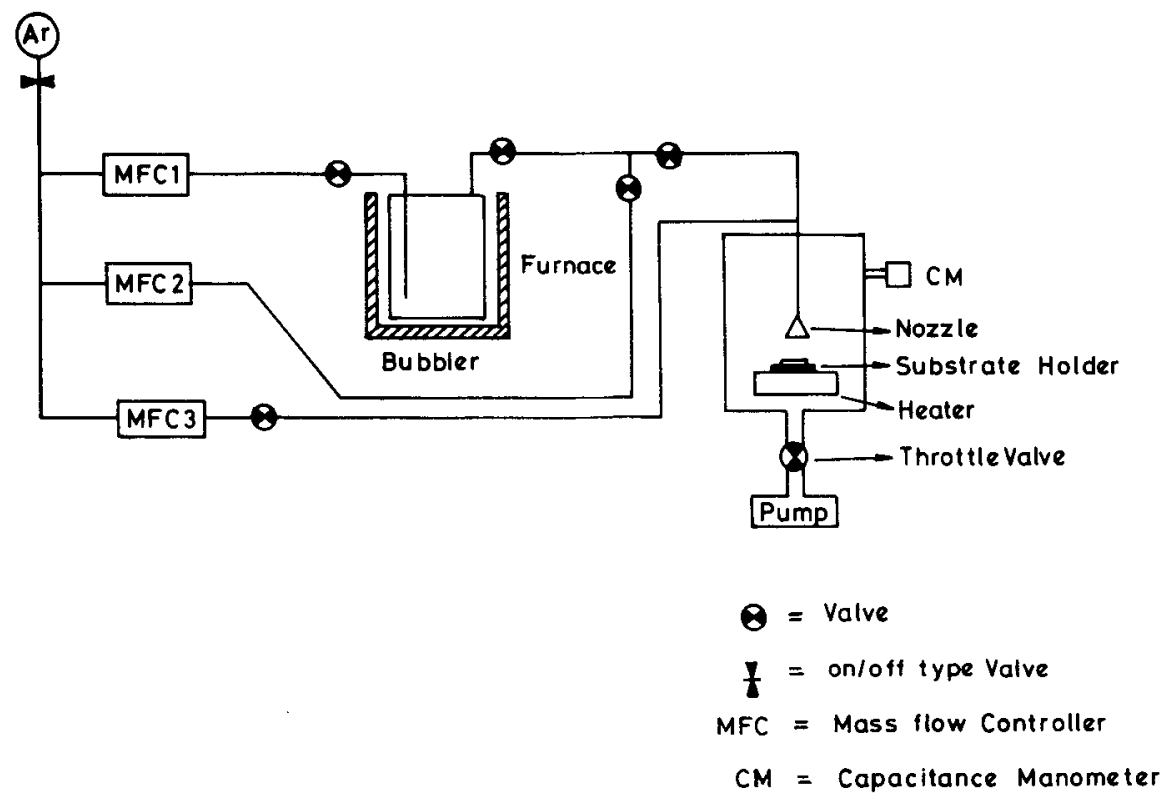

Figure 1. Schematic of the LPCVD reactor used for MOCVD deposition of copper thin films.

Table 2. Conditions for MOCVD growth of copper films.

\begin{tabular}{ll}
\hline Precursor & $\mathrm{Cu}(\mathrm{dpm})_{2}$ \\
Bubbler temperature & $120^{\circ} \mathrm{C}$ \\
Carrier gas & $250^{\circ} \mathrm{C}$ \\
line temperature & \\
Substrate temperature & $350^{\circ} \mathrm{C}$ \\
Carrier gas used & Argon \\
Carrier gas flow rate & $50 \mathrm{sccm}$ \\
Diluent gas flow rate & $150 \mathrm{sccm}$ \\
Pressure & $10 \mathrm{Torr}$ \\
Deposition time & $15-75 \mathrm{~min}$ \\
\hline
\end{tabular}




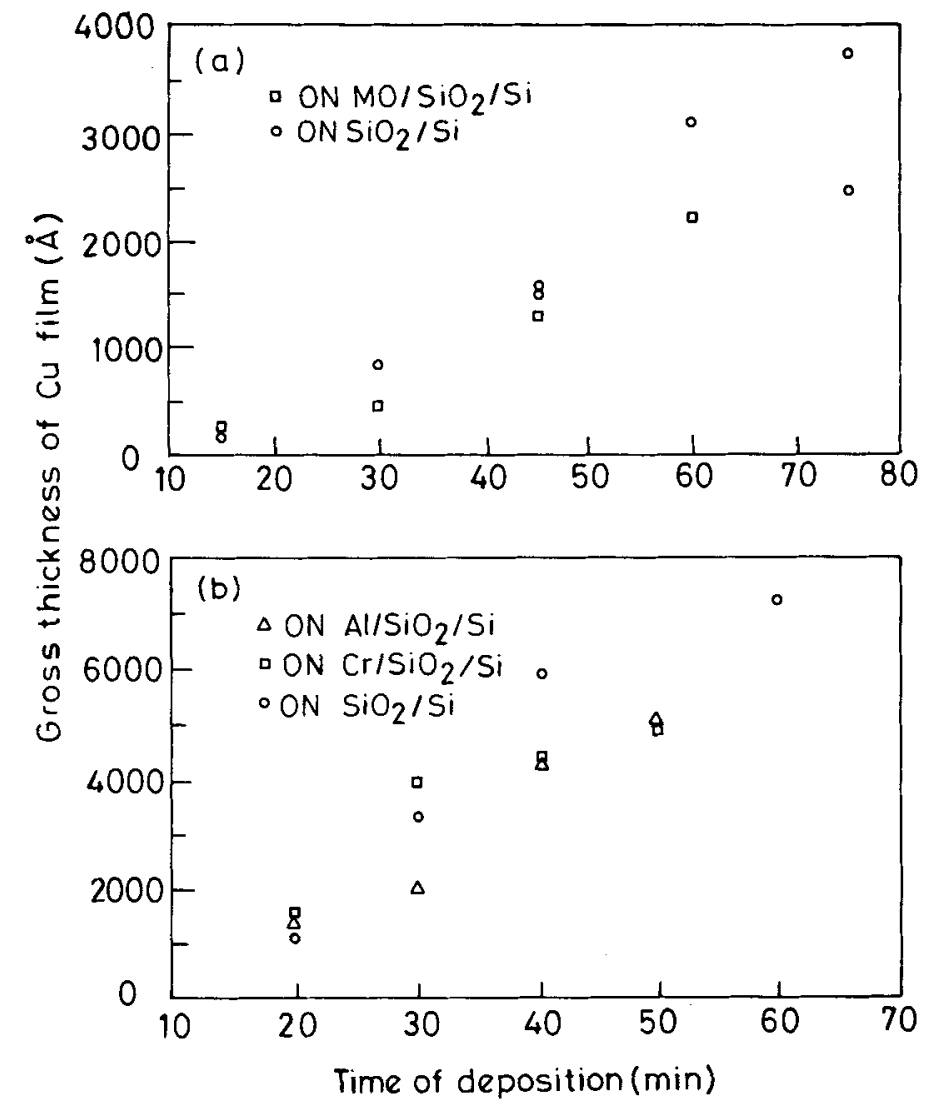

Figure 2. Film thickness vs deposition time for MOCVD growth of copper on different diffusion barrier/adhesion promoter layers.

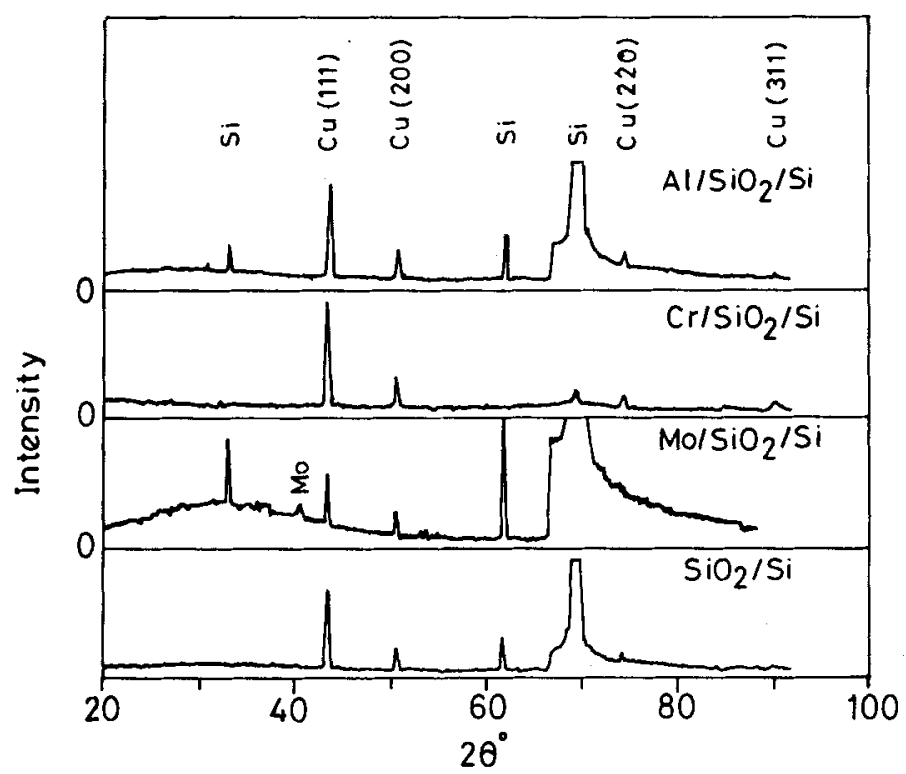

Figure 3. XRD pattern of MOCVD-grown copper films on different diffusion barrier/adhesion promoter layers. 


\subsection{Study of films grown}

Gross thickness of the films deposited were measured by weight change using a semimicro balance. Resistivity of the films grown on uncoated $\mathrm{SiO}_{2} / \mathrm{Si}$ wafers was measured by Văn der Pauw method. X-ray diffraction pattern of these films were recorded on a Phillips powder X-ray diffractometer. A scotch tape peeling test was performed as a qualitative test of film adhesion to the substrate. In this test, a narrow long piece of $3 \mathrm{M}$-Scotch tape was attached to the film and then the tape was pulled out. SEM micrographs of the copper films were taken using Cambridge Instruments and JEOL microscope. The electron beam energy was $20 \mathrm{kV}$ and the magnification was $1 \mathrm{k}-10 \mathrm{k}$.

\section{Results}

\subsection{Growth}

A plot of film thickness vs deposition time is given in figure 2. In general, growth is very slow at the beginning, followed by a steep increase in growth rate. On long depositions, a saturation limit is also identified. The growth rates of $\mathrm{Cu}$ films on different metal diffusion barrier/adhesion promoter layers were found to be lower than on bare $\mathrm{SiO}_{2} / \mathrm{Si}$.

\subsection{Resistivity and $X$-ray diffraction}

Resistivity of the films grown on $\mathrm{SiO}_{2} / \mathrm{Si}$ were found to be in the range of $2 \cdot 5 \mu \Omega-\mathrm{cm}$ to $20 \mu \Omega-\mathrm{cm}$ with very thin films $(\sim 300 \AA)$ showing highest resistivity. We believe that the actual resistivity of the thicker films is close to the bulk value of copper $(1 \cdot 7 \mu \Omega-\mathrm{cm})$, the higher value reported here being due to imprecise film thickness measurement and to the void structure of the films. It confirms the good quality of the deposited copper films. X-ray. diffraction analysis was performed to examine the crystalline quality of the films grown. Figure 3 gives XRD pattern of copper films grown on different diffusion barrier/adhesion promoter layers. These XRD patterns show that the deposited films were of pure polycrystalline copper. No preferred orientation of copper grains was found.

\subsection{Adhesion}

Scotch tape peeling tests demonstrated very good adhesion of the $\mathrm{Cu}$ films to the $\mathrm{SiO}_{2}$ surface. Though a few reports (Kaloyeros and Fury 1993; Ding et al 1994) claim poor adhesion of $\mathrm{Cu}$ on $\mathrm{SiO}_{2} / \mathrm{Si}$, films grown in our process show no blistering or delamination even at a thickness of $2000 \AA$. However, thicker films (>3000 $\AA$ ) on $\mathrm{SiO}_{2} / \mathrm{Si}$ showed minor delamination with (only) the top layer peeling off with the scotch tape. Films grown on metal adhesion promoter layer suffered no damage or deformation due to peel tests.

\subsection{Surface morphology}

Micrographs of very thin films, showing differing nucleation density on the barrier layers, are given in figure 4. On $\mathrm{SiO}_{2} / \mathrm{Si}$, very high density of nucleation was found, 
whereas on $\mathrm{Mo} / \mathrm{SiO}_{2} / \mathrm{Si}$ surface, nucleation density was very low. On $\mathrm{Cr} / \mathrm{SiO}{ }_{2} / \mathrm{Si}$ and $\mathrm{Al} / \mathrm{SiO}_{2} / \mathrm{Si}$, films were of thickness about $1300 \AA$ and are in the first phase of coalescence of grains, with a very high primary nucleation density.
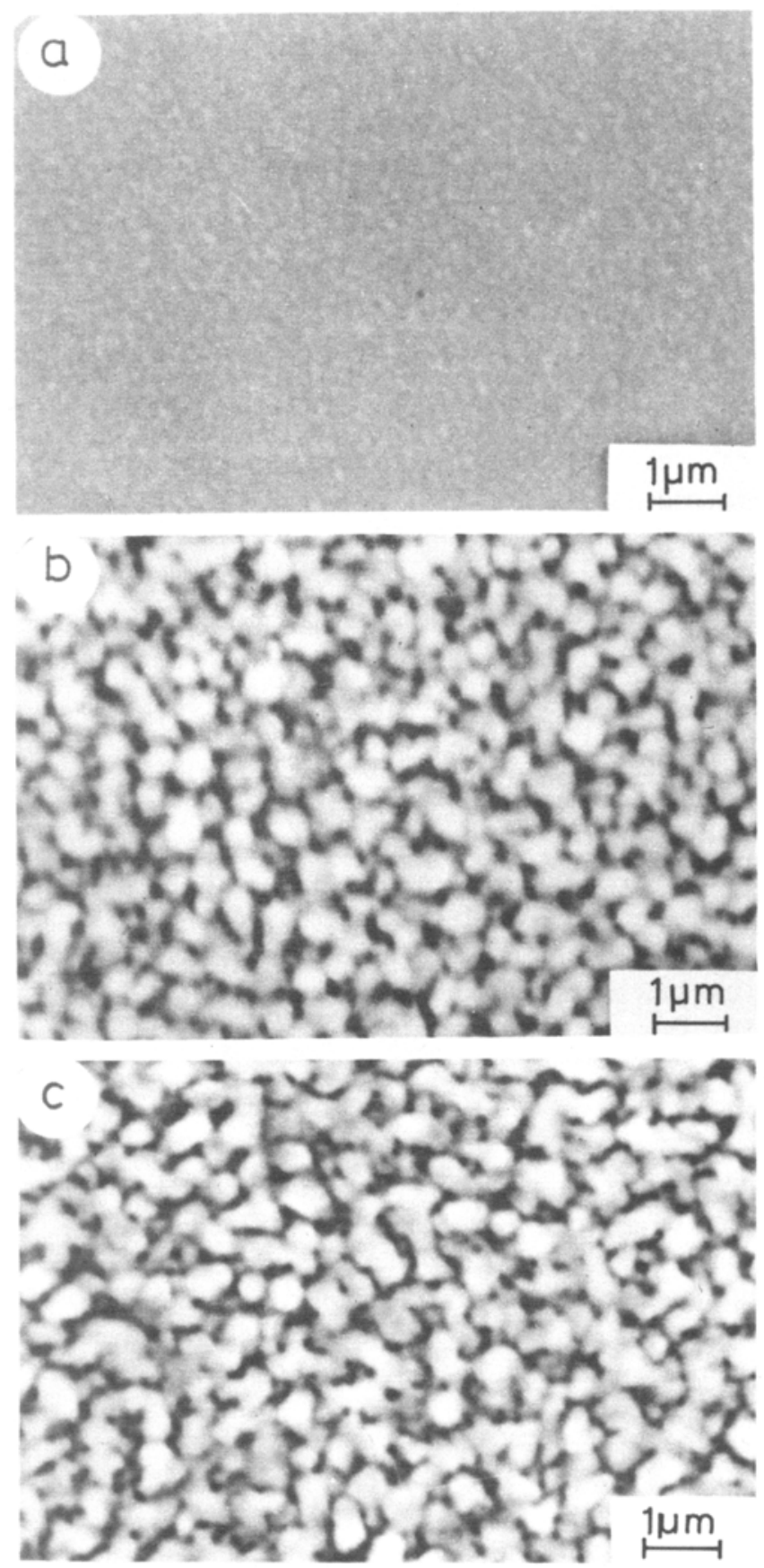

Figure 4. a-c. 


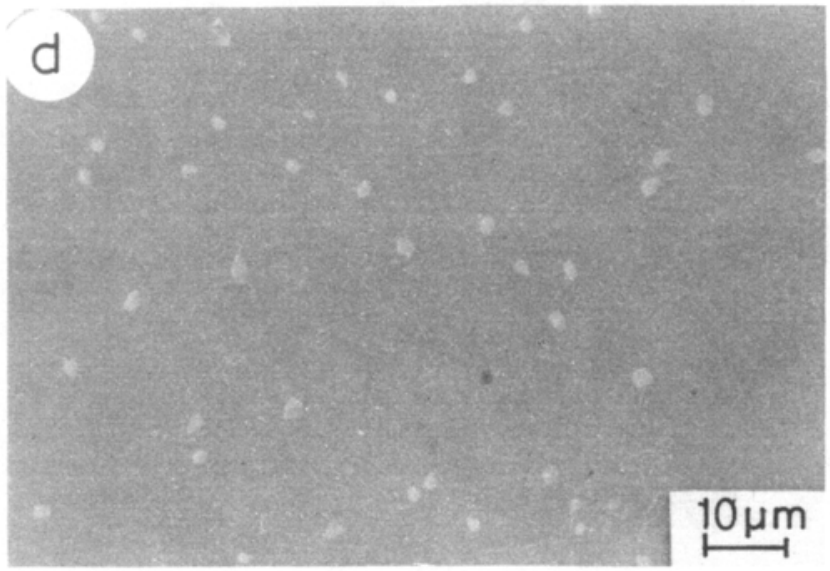

Figure 4. SEM micrograph of thin film of $\mathrm{Cu}$ of specified thickness on (a) $\mathrm{SiO}_{2} / \mathrm{Si}, 800 \AA$, (b) $\mathrm{Cr} / \mathrm{SiO}_{2} / \mathrm{Si}, 1400 \AA$, (c) $\mathrm{Al} / \mathrm{SiO}_{2} / \mathrm{Si}, 1300 \AA$ and (d) $\mathrm{Mo} / \mathrm{SiO}_{2} / \mathrm{Si}, 300 \AA$.
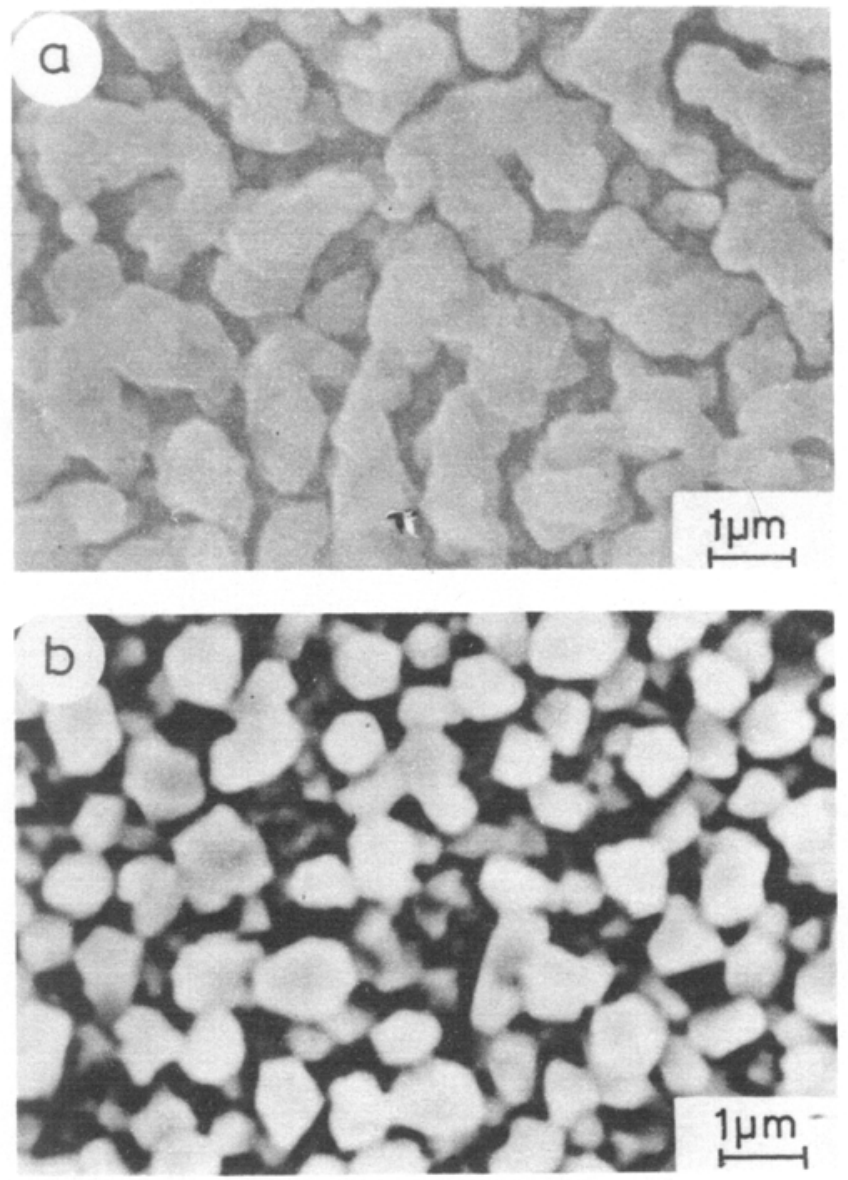

Figure 5. a-b. 

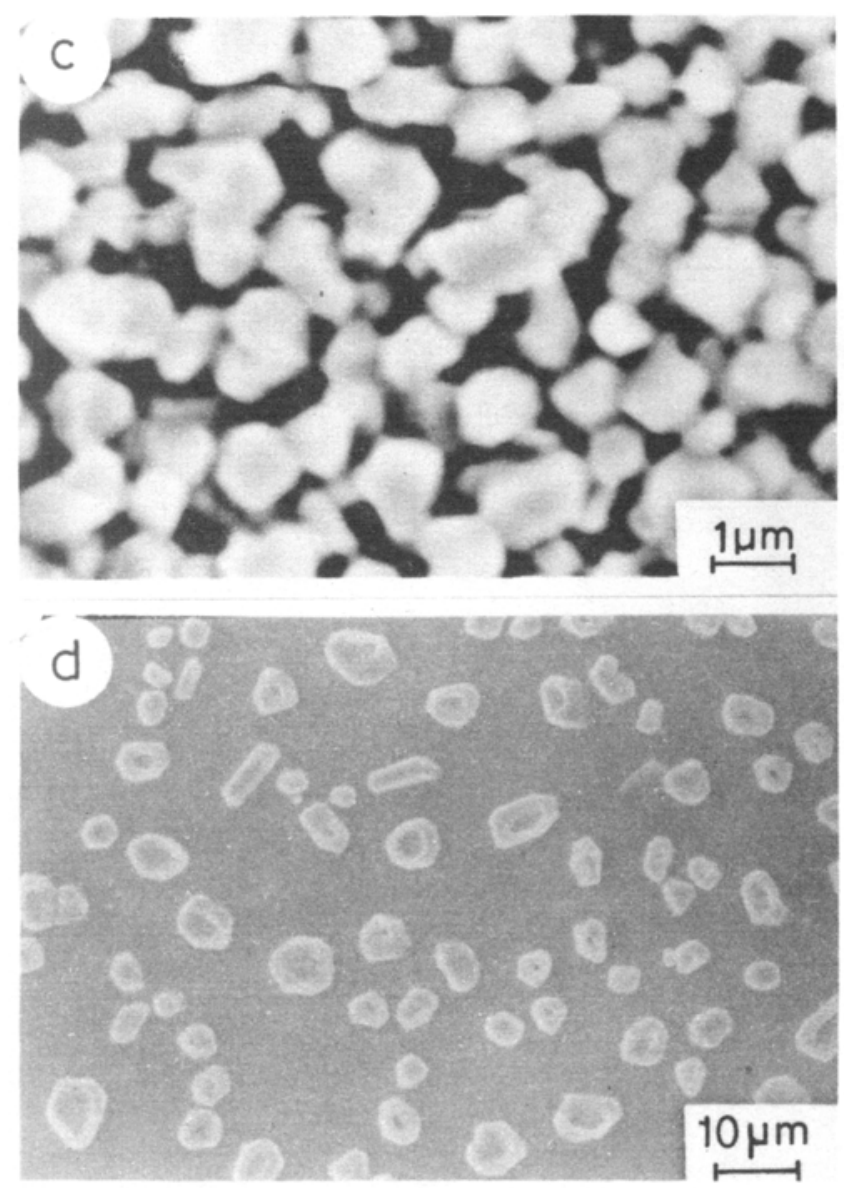

Figure 5. SEM micrograph of thin film of $\mathrm{Cu}$ of specified thickness on (a) $\mathrm{SiO}_{2} / \mathrm{Si}, 3800 \AA$, (b) $\mathrm{Cr} / \mathrm{SiO}_{2} / \mathrm{Si}, 4400 \AA$, (c) $\mathrm{Al} / \mathrm{SiO}_{2} / \mathrm{Si}, 4300 \AA$ and (d) $\mathrm{Mo} / \mathrm{SiO}_{2} / \mathrm{Si}, 2500 \AA$.

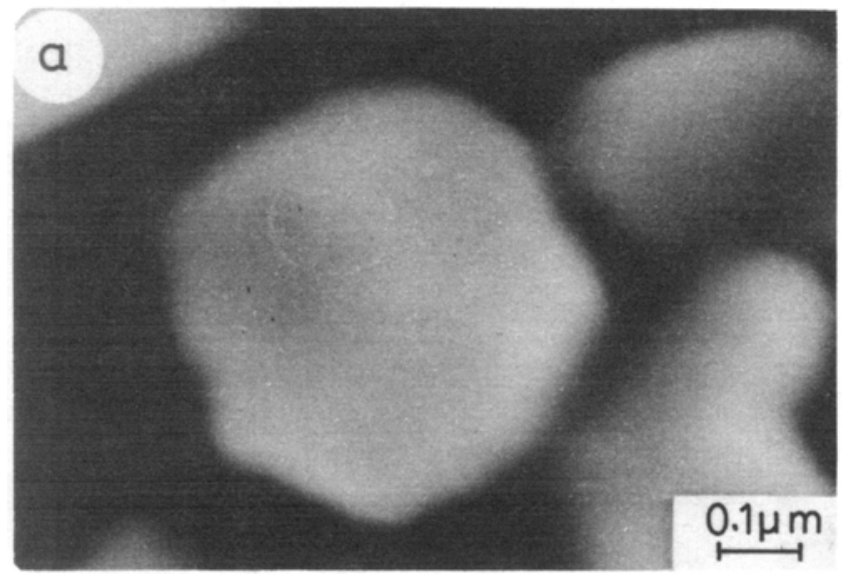

Figure 6. a. 

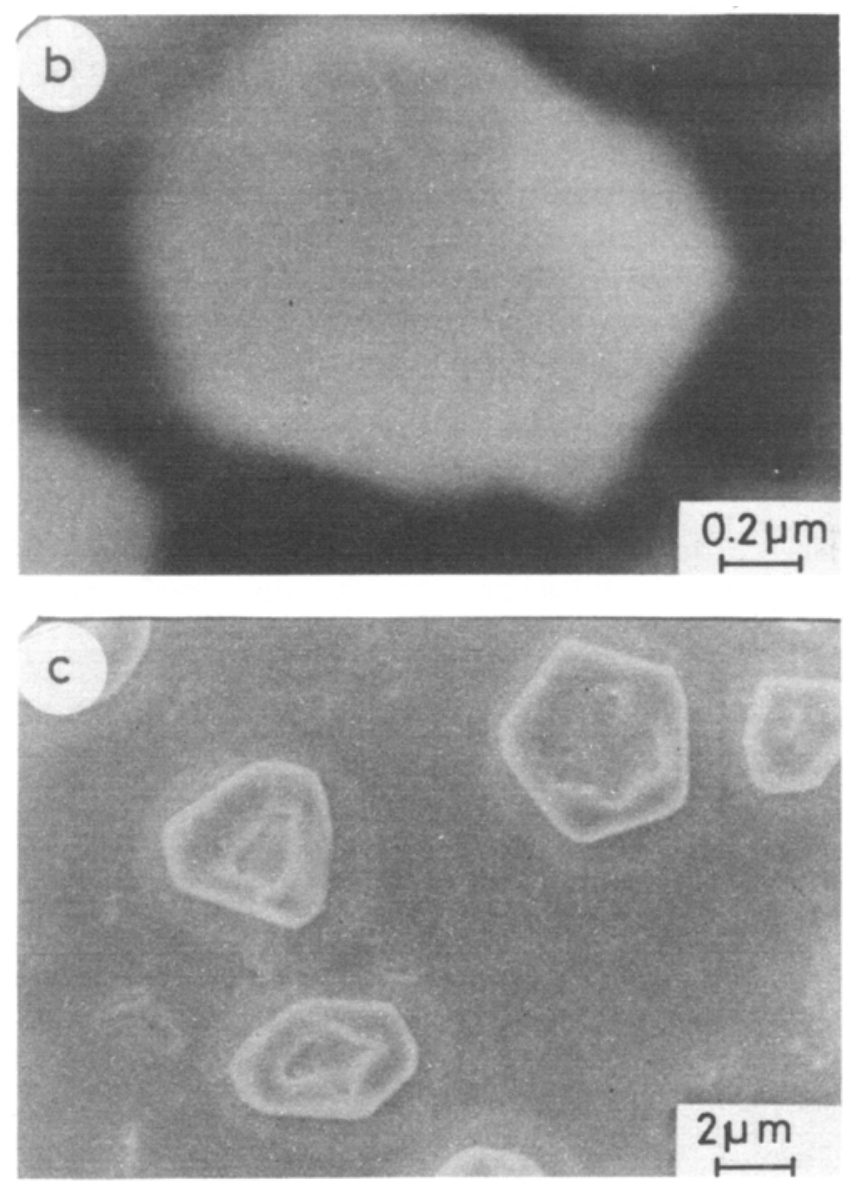

Figure 6. High magnification SEM micrographs of films as in figure 5: (a) $\mathrm{Cr} / \mathrm{SiO}_{2} / \mathrm{Si}$, (b) $\mathrm{Al} / \mathrm{SiO}_{2} / \mathrm{Si}$ and (c) $\mathrm{Mo} / \mathrm{SiO}_{2} / \mathrm{Si}$. The grain shapes are to be noted.

Micrographs of thicker films show significant grain growth in the films (figure 5). On $\mathrm{SiO}_{2} / \mathrm{Si}, \mathrm{Cr} / \mathrm{SiO}_{2} / \mathrm{Si}$ and $\mathrm{Al} / \mathrm{SiO}_{2} / \mathrm{Si}$ surfaces, the grains were interconnected and closely placed, giving a nearly $100 \%$ surface coverage, whereas on $\mathrm{Mo} / \mathrm{SiO}_{2} / \mathrm{Si}$, isolated large grains $(10-20 \mu \mathrm{m}$ in size) were found, giving a poor surface coverage $(\sim 40 \%)$. Another interesting feature is the structure of the grains. The films grown on metal surfaces show faceting in the grains (figure 6), whereas in films on $\mathrm{SiO}_{2} / \mathrm{Si}$, no such faceting was found.

\section{Discussion}

The general nature of the slow growth of the films at the beginning, followed by a higher rate of deposition, can be understood by invoking the concept of nucleation in a heterogeneous medium. Nucleation occurs out of supersaturation in the system. At the beginning, due to smaller size of the nuclei, the surface energy remains very high resulting in destruction of the nuclei until the size of the nuclei crosses critical value. After crossing this critical value, these nuclei grow rapidly, and then the growth rate becomes proportional to the nucleation density and adatom concentration. 
The differences in nucleation and grain growth on different surfaces can be understood by introducing the concept of surface mobility of the adatom. A high adatom mobility leads to a low nucleation density and finally to isolated grain growth. Some recent simulation studies (Xu and Lu 1994) also support these observations. However, most of these simulations are of a PVD process, where the adatom is itself the depositing atom. In CVD, the two species are often different and may have very different mobilities. Hence, the effect of change of surface mobility and deposition temperature is complex in nature. However, the gross features of island growth and formation of isolated large grains (as on $\mathrm{Mo} / \mathrm{SiO}_{2} / \mathrm{Si}$ ) can be clearly visualized using this simple concept.

\section{Acknowledgement}

The authors would like to thank Lakshmi Raghunathan and Anjana Devi for precursor synthesis and Prof. K V Ramanathan for useful discussions.

\section{References}

Ding P J, Wang W, Lanford W A, Hymes S and Murarka S P 1994 Appl. Phys. Lett. 651778

Goswami J, Shivashankar S A, Lakshmi R, Anjana D and Ramanathan K V 1994 MRS Symp. Proc. 337691

Kaloyeros A E and Fury M A 1993 MRS Bull. 1822 and references therein.

Murarka S P, Gutmann R J, Kaloyeros A E and Lanford W A 1993 Thin Solid Films 236257

Ohmi T and Tsubouchi K 1992 Solid State Technol. 3547

Schum-Diamand Y, Dedhia A, Hoffstetter D and Oldham W G 1993 J. Electrochem. Soc. 1402427

Sze S M 1985 Semiconductor devices, physics and technology (New York: Wiley)

Weber E R 1988 Properties of silicon (London: The Institute of Electrical Engg.) p. 420

Xu S and Lu G Q 1994 J. Mater. Sci. Lett. 131629 